\title{
A review on Spray pyrolysis deposited CZTS thin films for solar cell applications \\ C.S.A. Raj ${ }^{1}$, S. Sebastian ${ }^{1}$ and Susai Rajendran ${ }^{2}$
}

1. PG \& Research Department of Physics, Arul Anandar College, Karumathur, Madurai-Dt. 2. Department of Chemistry, St. Antony's College of Arts and Science for Women, Tamarapadi, Dindigul.

\begin{abstract}
$\mathrm{Cu}_{2} \mathrm{ZnSnS}_{4}$ generally abridged as CZTS is a potential material for economical thin film solar cells, due to its appropriate band gap energy of around $1.5 \mathrm{eV}$ and great absorption coefficient of above $10^{4} \mathrm{~cm}^{-1}$. All the constituents of this material are plentiful in the earth's crust, and they are non-hazardous making it an elegant alternative. Subsequent to the early achievement of the CZTS based solar cell with its light to electrical conversion efficiency of $0.6 \%$, significant advancement in this research area has been attained, particularly in the last seven years. Currently, the conversion effectiveness of the CZTS thin film solar cell has enhanced to 24\%. More than 500 papers on CZTS have been available and the greater part of these converses the preparation of CZTS thin films by diverse methods. Until now, many physical and chemical methods have been engaged for preparing CZTS thin films. Amongst them, spray pyrolysis is a flexible deposition technique. Spray pyrolysis is a simple deposition technique that finds use in widespread areas of thin film deposition research. This method is appropriate for depositing good quality films with low cost, clean deposition, and simplicity and flexibility in the manufacturing design. This script, reviews the synthesis of CZTS semiconductor thin films deposited by spray pyrolysis. This analysis initiates with a portrayal of the spray pyrolysis system, and then establish the CZTS and preparation of the CZTS precursor for coating. A review of spray pyrolysis of CZTS thin films are discussed in detail. To conclude, we present perspectives for advancements in spray pyrolysis for a CZTS based solar cell absorber layer.
\end{abstract}

Key words: CZTS, Spray pyrolysis, Thin films.

\section{Conventional Spray Pyrolysis Technique}

Spray pyrolysis technique is rooted in forming an aerosol from diverse precursor solutions of metallic salts or a colloidal solution. The created solution droplets are then very quickly heated in a furnace at specified temperature, thus transient throughout a number of stages: (1) disappearance of the solvent from the exterior of the droplets, (2) drying the droplets including the precipitated solute, (3) the annealing of the precipitate at elevated temperatures (4) growth of 
micro porous particles of definite phase composition, (5) creation of solid particles . In the spray pyrolysis process, preparation of consistent and fine droplets of reactants and their controlled thermal decomposition are tricky operations.

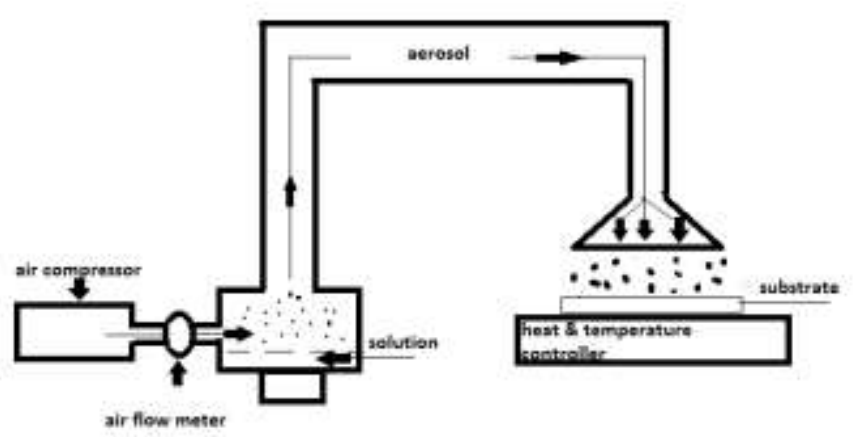

Fig 1. Conventional Spray Pyrolysis Unit.

Contrast with other synthetic methods, spray pyrolysis has a number of unique benefits. Mainly, due to its uncomplicated equipment and investigational set up, spray pyrolysis process is an economic method, and, similarly, it does not necessitate the utilization of premium reagents and the compositions. Moreover with different synthesis circumstances, the morphology and dimension of particles can be proficiently controlled. Spray pyrolysis method has several drawbacks, including (1) it is not simple to improve (2) oxidation of sulfides when processed in air atmosphere is possible; (3) there are some hurdles in determining the growth temperature. The spray pyrolysis method is economic and one of the leading methods through which porous films and films with high-density packaging and high uniformity of particles are obtained. It is also an essential technique for achieving ultrafine powders with small particle size $(<1 \mu \mathrm{m})$, narrow size distribution (1$2 \mu \mathrm{m})$, high purity, high porosity, and large surface area. Typical spray pyrolysis apparatus consists of an atomizer, precursor solution, substrate heater, and temperature controller (Fig.1) Spray pyrolysis method has been applied to deposit a wide range of thin films, which are used in different devices such as solar cells, sensors, and solid oxide fuel cells.

\section{Novel Nebulizer Spray Pyrolysis}

Nebulizer Spray pyrolysis is a method in which a nanostructure is obtained when a solution consists of a precursor is sprayed by a nano porous nebulizer against the hot substrate in the furnace, leading to the decomposition of the precursor to form the final preferred material on the substrate. The nanostructure parameters like particle size, shape, and thickness are altered by controlling the spray energy (gas inlet to nebulizer, gas flow pressure), droplet size of the precursors, time duration of spray, distance between the spray gun and the substrate, and the 
temperature of the furnace and substrate using manual or automated control systems. Nebulizer spray pyrolysis is very helpful for the preparation of nano thin films and clusters at large scale, if the parameters can be maintained constant. Examples of this are $\mathrm{Cu}, \mathrm{TiO}_{2}, \mathrm{CdS}$, and $\mathrm{CdSe}$.

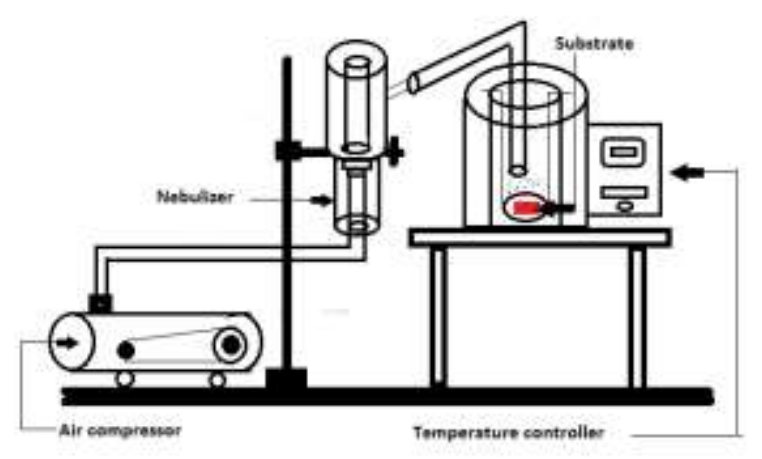

Fig 2. Nebulizer Spray Pyrolysis Unit.

\section{Copper Zinc Tin Sulfide (CZTS):-}

The main outstanding prospect energy asset is the solar energy due to its adequate infinite existence, unlimited power, and little effects on the surroundings. Although the Si-based solar cells have high efficiency, utilizing these solar cells is limited owing to less flexibility, heavy weight, and high cost of installation. Bearing in mind, many alternatives have been enquired to build up flexible, light weight, economic, high efficiency solar cells. Additionally, there has been an improved recall on utilizing plentiful economical and environmental friendly materials in fabricating thin film solar cells.

The $\mathrm{I}_{2}$-II-IV-VI $\mathrm{V}_{4}$ quaternary semiconducting compound $\mathrm{Cu}_{2} \mathrm{ZnSnS}_{4}$ (CZTS) which looks like a greenish black crystal is an appropriate potential substance for solar cell due to its suitable band-gap energy of about $1.5 \mathrm{eV}$ and high optical absorption coefficient over $10^{4} \mathrm{~cm}^{-1}$ [1-4]. Contrast to the element In and Ga used in the film of $\mathrm{CuInGaSe}_{2}(\mathrm{CIGS})$, the $\mathrm{Zn}$ and $\mathrm{Sn}$ in the CZTS are nontoxic and plentiful. Copper zinc tin sulfide thin film shows potential of capturing sunlight and converting it into electricity. Structural, optical and electrical properties of this layer have a deep impact on the whole performance of the solar cell. So the CZTS thin film is the inexpensive environment friendly absorber layer for thin film solar cell. So far, the reported vacuum methods for fabricating CZTS thin films consist of pulsed laser deposition [5], magnetron sputtering [6] and fast co-evaporation method [7], which are 
comparatively expensive since ultra-high vacuum equipment is required. Also, there are some inexpensive non-vacuum solution techniques for the preparations of CZTS thin films, such as sol-gel [8], electrodeposited [9], and spray pyrolysis [10].

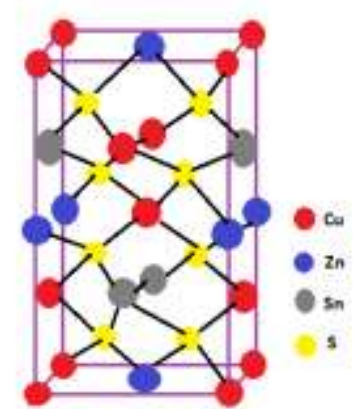

(a) Kenterite CrTs

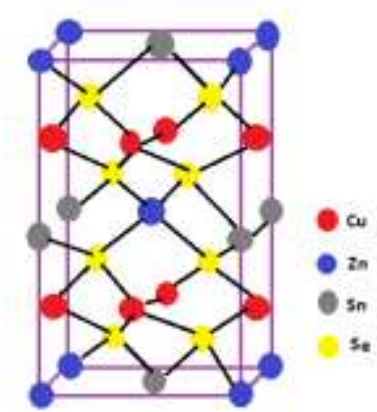

(b) Stannite carse

Fig 3. The unit cell of tetragonal (a) kesterite CZTS and (b) stannite CZTS

Table 1. Physical properties of CZTS Thin Films [11, 12].

\begin{tabular}{|c|l|l|}
\hline S.NO & Parameters & \multicolumn{1}{|c|}{ Properties } \\
\hline 1 & $\begin{array}{l}\text { Chemical } \\
\text { formula }\end{array}$ & $\mathrm{Cu}_{2} \mathrm{ZnSnS}_{4}$ \\
\hline 2 & $\begin{array}{c}\text { Molecular } \\
\text { weight }\end{array}$ & $439.47 \mathrm{gram} / \mathrm{mol}$ \\
\hline 3 & Density & $4.5 \mathrm{~g} \mathrm{~g} / \mathrm{cm}^{3}$ \\
\hline 4 & $\begin{array}{c}\text { Melting } \\
\text { point }\end{array}$ & $999^{\circ} \mathrm{c}\left(1810^{\circ} \mathrm{F} ; 1260 \mathrm{~K}\right)$ \\
\hline 5 & $\begin{array}{l}\text { Boiling } \\
\text { point }\end{array}$ & $\mathrm{N} / \mathrm{A}$ \\
\hline 6 & $\begin{array}{c}\text { Solubility in } \\
\text { water }\end{array}$ & Insoluble \\
\hline 7 & Solubility & Soluble in acids and alkalis \\
\hline
\end{tabular}

\section{Preparation of precursor solution}

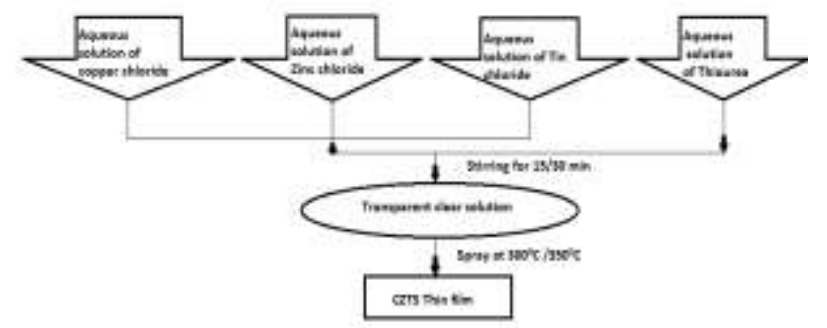

Fig. 1. Schematic diagram of the solution based spray pyrolysis route for CZTS thin films. 
CZTS thin films be processed by spray pyrolysis method onto microscopic glass slides from a precursor solution consisting of copper chloride $(\mathrm{CuCl} 2)$, zinc chloride $(\mathrm{ZnCl} 2)$, tin chloride (SnCl4) and thiourea [(NH2)2CS] with deliberately in excess concentration, dissolved in distilled water using magnetic stirrer to get a clear solution. Few drops of $\mathrm{HCl}$ were added as a stabilizing agent. Appropriate substrate temperature is needed for good adherence of the film to the substrate. For thin film deposition, the nozzle-to-substrate distance may be atleast $15-30 \mathrm{~cm}$, whereas a solution flow rate of $5 \mathrm{ml} / \mathrm{min}$ with air as carrier gas at pressure of $68.95 \mathrm{kPa}$ and spraying time of 30 is required [13]. The samples were allowed to cool to room temperature and then taken out for the characterization.

\section{Review of CZTS Thin Films:}

\section{Impact of stoichiometric and optimal compositional ratios:}

Arvind Chavda, et al [14], synthesized CZTS thin films on a F:SnO2 and soda lime glass substrates by spray pyrolysis method. The prepared samples were post treated by rapid thermal processing method of sulfurization to increase the stoichiometry and crystallinity of the film. The structural, optical, surface morphology and electrical properties of RTP sulfurized films were studied by them. The X-ray diffraction pattern revealed the development of tetragonal CZTS phase, and is confirmed by Raman analysis. They found that the sulfurized film exhibited better crystallinity and improved stoichiometry. The optical and electrical data reveal the direct optical band gap, bulk carrier concentration and resistivity of $1.5 \mathrm{eV}, 2.28 \times 1018 \mathrm{~cm}-3$ and $1.21 \Omega / \mathrm{cm} 2$, respectively.

Maykel Courel, et al [15], assessed the CZTS thin films physical properties processed beneath stoichiometric $(\mathrm{Cu} 2 \mathrm{ZnSnS} 4)$ and best $(\mathrm{Cu} 1.6 \mathrm{Zn} 1.1 \mathrm{Sn} 0.9 \mathrm{~S} 4)$ compositional ratios by spray pyrolysis technique. They studied the effect of different substrate temperatures on the optical, electrical, morphology and structural properties bearing in mind both compositional conditions. They performed characterization techniques such as EDX, AFM, Raman, XRD, XRF, transmittance and reflectance measurements, I-V, I-T and Hall measurements and confirmed that samples coated beneath finest compositional ratios shows superior morphological and structural properties in addition to lower involvement of secondary phases along with band-gap energy values close to to $1.5 \mathrm{eV}$ as requisite for solar cell applications. 


\section{Effect of post deposition annealing:}

Tarun Chandel, et al [16], coated single phase nanocrystalline (CZTS) thin films by the spray pyrolysis method. Using glass substrates the films were coated at $300^{\circ} \mathrm{C}$ and were consequently vacuum annealed for $1 \mathrm{hr}$, at various temperatures ranging from $350^{\circ} \mathrm{C}$ to $500^{\circ} \mathrm{C}$. XRD studies reveal that the films crystallize in the CZTS kesterite structure fit in to the tetragonal structure. XRD, AFM and SEM studies showed that the vacuum annealed films are made up of nano-sized (below $15 \mathrm{~nm}$ ) particles of CZTS. Optical studies reveal that the optical band gap values are alike with the reported values for thin film CZTS.

Chan Kim \& Sungwook Hong [17], fabricated CZTS thin films using spray pyrolysis method. The films were annealed in air at annealing temperatures of $350-550^{\circ} \mathrm{C}$ in increments of $50^{\circ} \mathrm{C}$ for annealing durations of 1,2, and $3 \mathrm{~min}$. The prepared films were investigated using X-ray diffraction, field-emission scanning electron microscopy (FE-SEM), and ultraviolet visible nearinfrared (UV-Vis-NIR) spectrometer. They found that the best CZTS film is a film annealed at $500^{\circ} \mathrm{C}$ for $1 \mathrm{~min}$, which had modest properties for fabricating a solar cell device; its band gap energy was found to be $1.46 \mathrm{eV}$ respectively.

Tarun Chandel, et al [18], coated CZTS thin films on soda lime glass substrates at $300^{\circ} \mathrm{C}$. Aqueous solutions of copper chloride, zinc chloride, stannous chloride and thiourea were used as precursors and were mixed well to obtain the spray liquid. The films were annealed in vacuum at $350^{\circ} \mathrm{C}, 400^{\circ} \mathrm{C}$ and $450^{\circ} \mathrm{C}$ after deposition. Structural and optical characterization was carried out on the CZTS films using X-ray diffraction and UV-VIS spectrophotometry. XRD results showed that the films are single phase nanocrystalline CZTS. Optical studies revealed that the optical gap values are $1.44 \mathrm{eV}$ for the as-grown film and $1.46 \mathrm{eV}, 1.48 \mathrm{eV}$ and $1.49 \mathrm{eV}$ for the films annealed at $350^{\circ} \mathrm{C}, 400^{\circ} \mathrm{C}$ and $450^{\circ} \mathrm{C}$, respectively.

Bwamba Jonah A, et al [19], deposited CZTS thin films on soda-lime glass (SLG) substrate using electrostatic field-assisted economic spray pyrolysis method. The precursor solution, with $\mathrm{Cu}_{2} \mathrm{Cl}, \mathrm{ZnCl}_{2}, \mathrm{SnCl}_{4}$ and thiourea at optimized concentrations, was sprayed on heated SLG substrate at a flow rate of $0.33 \mathrm{ml} / \mathrm{min}$. The deposition was done at fixed substrate temperatures of $300^{\circ} \mathrm{C}$ with different precursor concentrations. After coating, the films were annealed at a temperature of $350^{\circ} \mathrm{C}$ in argon atmosphere for 60minutes. The XRD pattern revealed a peak at the $2 \theta$ position of $31.7200^{\circ}$ with a FWHM of $0.3600^{\circ}$ and d-spacing of $2.81863 \AA$. The annealed CZTS films were found to be polycrystalline orthorhombic structure, which is confirmed from 
XRD results. The average sheet resistance of the films is in the region of $7.264 X 107 \Omega$ sq of thickness 100nm under dark conditions. The film micrograph acquired using Carl Zeiss optical interference microscope confirmed light agglomeration of grains and voids of sparcely dispersed films.

\section{Influence of copper concentration}

S. Mahjoubi, et al [20], studied the cause of copper concentration $(0.01$ to $0.04 \mathrm{M})$ on the optical, morphological and structural properties of CZTS thin films. The XRD results have revealed the development of polycrystalline CZTS thin films. They found that the raise in the copper concentration has enhanced the crystallinity of the CZTS thin films. The optical band gap was calculated to be $1,1.8$ and $1.6 \mathrm{eV}$ respectively for copper concentration $0.02,0.03$ and $0.04 \mathrm{M}$.

K.G. Deepa, et al [21], deposited Cu2ZnSnS4 films by ultrasonic spray pyrolysis method. They investigated the optoelectronic properties by varying $\mathrm{Zn}$ and $\mathrm{Sn}$ compositions in the film. The prepared Films illustrate a tetragonal kesterite structure by privileged orientation along the (112) plane. They found that the sample with the maximum $\mathrm{Cu}$ concentration revealed the least band gap of $1.46 \mathrm{eV}$.

In a further investigation, Deepa K.G. and Gauthaman Chandrabose [22], used an automated ultrasonic spray pyrolysis setup to coat CZTS thin films. They varied Sn concentration to achieve properties appropriate for solar cell applications. Kesterite tetragonal structured CZTS phase was prevailing in the entire films. When $\mathrm{Cu} /(\mathrm{Zn}+\mathrm{Sn})>0.83$, films revealed $\mathrm{Cu}_{2} \mathrm{~S}$ phase besides CZTS phase. Film is almost stoichiometric when $\mathrm{Cu} /(\mathrm{Zn}+\mathrm{Sn})$ concentration ratio in the precursor solution is 1.07. When $\mathrm{Sn}$ concentration is condensed, $\mathrm{Cu}$ concentration increased proportionally and a remarkable transform in morphology aroused for the $\mathrm{Cu}$-rich films. Every samples are of p-type in character with resistivity varies between 255 and $0.9 \times 10^{-3} \mathrm{ohm} \mathrm{cm}$. Sample with $\mathrm{Cu} /(\mathrm{Zn}+\mathrm{Sn})$ ratio of 0.83 is appropriate for solar cell applications.

\section{Impact of varying molar concentration:}

Kiran Diwate, et al [23], deposited thin films of CZTS by spray pyrolysis on glass (SLG) substrates with different sulphur molar concentration. They used Copper chloride, zinc chloride, tin chloride and thiourea as precursor materials. They studied the Influence of sulphur variant on the optical, electrical, morphology and structural properties of CZTS films using a variety of 
characterization techniques such as Raman spectroscopy, low angle XRD, FE-SEM, four probe methods, UV-Visible spectroscopy, etc. The creation of CZTS was established by Raman spectroscopy and low angle XRD. The structural investigation revealed arrangement of kesterite tetragonal phase with favored (112) direction. The energy gap values of CZTS thin films were found in the range $2-2.25 \mathrm{eV}$ over the complete array of sulphur variation studied. The cause for the difference in energy gap may perhaps because of quantum confinement effects at nanoscale. The morphological studies of Kiran Diwate, et al, showed arrangement of islands of nanoscale particulate clusters which comprise the films in the majority of the samples. The films show advanced resistivity values (in $\mathrm{K} \Omega$ ) due to occurrence of the strain in the films.

\section{Influence of substrate temperature:}

S. A. Khalate, et al [24], deposited CZTS thin films using spray pyrolysis method at diverse substrate temperatures. They reported the influence of substrate temperature on the optical, morphological, compositional and structural properties. From the XRD and Raman analysis they found that the prepared CZTS thin film show kesterite phase devoid of any secondary phases. Also the internal compressive stress unperturbed with substrate temperature for all CZTS thin films. The harmonized character of CZTS thin films were pragmatic from chemical composition and surface morphology study. The optical study endow with improved optical absorption $\left(10^{4}\right.$ $\mathrm{cm}^{1}{ }^{1}$ ) in the visible region and energy gap was reduced and initiate pretty close to the most favorable value of about $1.57 \mathrm{eV}$ to $1.49 \mathrm{eV}$ for solar cell application.

Srinivasan Thiruvenkadam, et al [25], used spray pyrolysis technique to coat CZTS thin films on soda lime glass substrates. They investigated the impact of variant of substrate temperature on the optoelectronic and structural properties. The XRD studies revealed that the crystallinity was enhanced by rising substrate temperature and a polycrystalline nature with (112), (220) and (116) phases were obtained. AFM was used to investigate the surface morphology of the films. They found that the average roughness and grain size increases as the substrate temperature increases. Using UV-Vis-NIR spectrometer, they calculated the optical energy band gap of the films and was found to be 1.40-1.60 eV which is almost near the optimum band gap of CZTS based solar cell.

W. Daranfed, et al [26], coated CZTS thin films by ultrasonic spray pyrolysis technique. They varied the substrate temperature from $280^{\circ} \mathrm{C}$ to $360^{\circ} \mathrm{C}$ to examine its influence on CZTS films 
properties. The deposition rate showed two activation energies 0.16 and $0.53 \mathrm{eV}$, respectively at low and high substrate temperatures. This revealed that CZTS deposition by spray pyrolysis passes by two dissimilar processes by rising substrate temperature. The temperature $320^{\circ} \mathrm{C}$ corresponds to the changeover between these two processes. The XRD studies revealed that the coated films have a kesterite hexagonal structure with (112) favored alignment and a crystalline size, varied from 30 to $52 \mathrm{~nm}$ with escalating substrate temperature. Stannate $\mathrm{ZnSnO}_{3}$ is there as a secondary phase. They found that the occurrence of this secondary phase leads to films optical band broadening. Broad emissions at roughly $1.27 \mathrm{eV}$ was pragmatic in the photoluminescence spectrum intended at $77 \mathrm{~K}$, it is go together with a small peak positioned at $1.75 \mathrm{eV}$ due the occurrence of zinc stannate phase $\mathrm{ZnSnO} 3$.

\section{Impact of film thickness:}

N. M. Shinde, et al [27], coated CZTS thin films on glass substrates by spray pyrolysis method. They investigated the thickness reliant (244-754 nm) optical, structural, morphological and electrical properties of CZTS films. The X-ray diffraction studies showed the creation of polycrystalline CZTS films. The SEM image showed the creation of even, condensed and consistent CZTS surface. Absorption coefficient was of the order of $10^{4} \mathrm{~cm}^{-1}$ and based on the film thickness the direct changeover was observed with energy gap in the series from 1.6 to $1.67 \mathrm{eV}$. The thermo emf measurement revealed that the CZTS films exhibited p-type electrical conductivity.

\section{Effect of starting-solution pH:}

Y. B. Kishore Kumar, et al [28], effectively coated CZTS thin films on glass at a substrate temperature of $643 \mathrm{~K}$. They studied the effect of starting-solution $\mathrm{pH}$ on the properties of the developed films. They varied the solution $\mathrm{pH}$ in the range 3.0 to 5.5. The films were characterized by studying their optical, structural and electrical properties. XRD patterns reveal that polycrystalline CZTS films with kesterite structure may possibly be produced by a solution with $\mathrm{pH}=3.0$. They found that the films are nonstoichiometric and may have binary phases in the amorphous form. Films coated by a solution with $\mathrm{pH}=4.5$ have binary phases along with CZTS. The lattice parameters of CZTS films are found to be $\mathrm{a}=0.542 \mathrm{~nm}$ and $\mathrm{c}=1.085 \mathrm{~nm}$. The optical band gap of these films is $1.45 \mathrm{eV}$ and the optical absorption coefficient is $>10^{4} \mathrm{~cm}^{-}$ 1 . 


\section{Impact of spray duration:}

N. Kamoun, et al [29], studied growth circumstances and several properties of sprayed CZTS thin films in order to establish the most excellent preparation conditions for CZTS based solar cells. The thin films are developed by spraying aqueous solutions containing zinc chloride, copper chloride, tin chloride and thiourea on heated glass substrates at diverse temperatures. They optimized the growth circumstances of the CZTS films with two sequences of experiments. In the first sequence the spray time was set at $30 \mathrm{~min}$ and in the second it is fixed at $60 \mathrm{~min}$. They varied the substrate temperature in each sequence from $553 \mathrm{~K}$ to $633 \mathrm{~K}$. From the investigation of XRD results, the finest crystallinity was attained for $613 \mathrm{~K}$ as substrate temperature and $60 \mathrm{~min}$ as sprayed duration. Furthermore, these CZTS films show evidence of the kesterite structure with favored orientation along the [112] direction. After annealing, they calculated the optical energy band-gap of the CZTS thin film with finest crystallinity as $1.5 \mathrm{eV}$ and is very near to the most favorable range for a solar cell.

\section{Recommendations and Conclusion:}

Due to uncomplicated nature and more economic over other leading techniques, spray pyrolysis method would be preferable in order to obtain porous films with high uniformity of particles. Over the conventional techniques, novel automated nebulizer spray pyrolysis technique would be preferred for synthesizing nano thin films at a large scale.

CZTS thin films with most excellent synthesis conditions with good crystallinity would be obtained by novel nebulizer spray pyrolysis technique with starting solution $\mathrm{pH}$ values in the range $(3.0-5.5)$, with maximum copper concentration of $0.04 \mathrm{M}$ and a spray duration of 30-60 minutes at a substrate temperature ranging from $340^{\circ} \mathrm{C}$ to $360^{\circ} \mathrm{C}$ with film thickness in the range $(300 \mathrm{~nm}-700 \mathrm{~nm})$ and annealed at temperatures ranging from $350^{\circ} \mathrm{C}$ to $500^{\circ} \mathrm{C}$ for $30 \mathrm{~min}-60$ minutes duration.

\section{References:}

[1] H. Katagiri, N. Sasaguchi, S. Hando, S. Hoshino, J. Ohashi, T. Yokota, Sol. Energy Mater. Sol. Cells 49 (1997) 407-414.

[2] M. Kumar, A. Dubey, N. Adhikari, S. Venkatesan, Q. Qiao, Energy Environ. Sci. 8 (2016) 31343159.

[3] S.Y. Li, C. Hägglund, Y. Ren, J.J.S. Scragg, J.K. Larsen, C. Frisk, Sol. Energy Mater. Sol. Cells 149 (2016) 170-178. 
[4] S.A. Vanalakar, G.L. Agawane, S.W. Shin, M.P. Suryawanshi, K.V. Gurav, K.S. Jeon, P.S. Patil, C.W. Jeong, J.Y. Kim, J.H. Kim, J. Alloy. Comp. 619 (2015) 109-121.

[5] A.V. Moholkar, S.S. Shinde, A.R. Babar, K.U. Sim, H.K. Lee, K.Y. Rajpure, P.S. Patil, C.H. Bhosale, J.H. Kim, J. Alloy. Comp. 509 (2011) 7439-7446.

[6] J.X. Xu, Z.M. Cao, Y.Z. Yang, Z.W. Xie J. Renew. Sustain. Energy 6 (2014) 5564-5576.

[7] B.A. Schubert, B. Marsen, S. Cinque, T. Unold, R. Klenk, Prog. Photovoltaics Res. Appl. 19 (2011) 93-96.

[8] Z.H. Su, K.W. Sun, Z.L. Han, H.T. Cui, F.Y. Liu, Y.Q. Lai, J. Li, X.J. Hao, Y.X. Liu, M.A, J. Mater. Chem. A. 2 (2013) 500-509.

[9] M.I. Khalil, O. Atici, A. Lucotti, S. Binetti, A.L. Donne, L. Magagnin, Appl. Surf. Sci. 379 (2016) 91-97.

[10] V.G. Rajeshmon, C.S. Kartha, K.P. Vijayakumar, C. Sanjeeviraja, T. Abe, Y. Kashiwaba, Sol. Energy 85 (2011) 249-255.

[11] Guen L, Glaunsinger WS., J Solid State Chem 1980;35:10-21.

[12] Matsushita H, Ichikawa T, Katsui A., J Mater Sci 2005; 40(E8).

[13] Kiran Diwate, et al, Energy Procedia 110 (2017) 180 - 187.

[14] Arvind Chavda, Biren Patel, Synthesis and characterization of spray deposited CZTS thin films for photo electrochemical application, AIP Conference Proceedings 1961, 030044 (2018)

[15] Maykel Courel et al, Mater. Res. Express (2018)

[16] Tarun Chandel, et al, Growth and Properties of Sprayed CZTS Thin Films, The Minerals, Metals \& Materials Society (2018)

[17] Chan Kim \& Sungwook Hong,Molecular Crystals and Liquid Crystals, (2017) 645:1, 217-224.

[18] Tarun Chandel, et al, Advanced Materials and Radiation Physics (AMRP-2015) AIP Conf. Proc. $1675,020032-1-4$.

[19] Bwamba Jonah A, et al, American Journal of Materials Science 2014, 4(3): 127-132.

[20] S. Mahjoubi, et al, N. Bitri, M. Abaab, I. Ly, Effect of copper concentration on the characteristics of Cu2ZnSnS4 (CZTS) thin films, Materials Letters (2018)

[21] K.G. Deepa, et al, Opto-Electronic Properties of Cu2ZnSnS4 Thin Films Grown by Ultrasonic Spray Pyrolysis, Journal of ELECTRONIC MATERIALS (2017)

[22] Deepa K.G.,et al, J. Anal. Appl. Pyrolysis,(2016)

[23] Kiran Diwate, et al, Energy Procedia 110 (2017) 180 - 187.

[24] S. A. Khalate, et al, Effect of deposition temperature on the properties of Cu2ZnSnS4 (CZTS) thin films, Superlattices and Microstructures (2017)

[25] Srinivasan Thiruvenkadam, et al, The influence of deposition temperature in the photovoltaic properties of spray deposited CZTS thin films,Solar Energy (2014)

[26] W. Daranfed, et al, Journal of Alloys and Compounds 542 (2012) 22-27.

[27] N. M. Shinde, et al, Properties of spray deposited Cu2ZnSnS4 (CZTS) thin films, J. Anal. Appl. Pyrolysis(2012)

[28] Y. B. Kishore Kumar, et al, P hys. Status Solidi A 206, No. 7, (2009) 1525-1530

[29] N. Kamoun, et al, Thin Solid Films 515 (2007) 5949-5952 